\title{
Development of Potato Late Blight Epidemics: Disease Foci, Disease Gradients, and Infection Sources
}

\author{
Maarten J. Zwankhuizen, Francine Govers, and Jan C. Zadoks
}

First, second, and third authors: Laboratory of Phytopathology, Wageningen Agricultural University, P.O. Box 8025, 6700 EE, Wageningen, the Netherlands; first and third authors: C. T. de Wit Research School of Production Ecology; and second author: Graduate School Experimental Plant Sciences.

Accepted for publication 19 April 1998.

\begin{abstract}
Zwankhuizen, M. J., Govers, F., and Zadoks, J. C. 1998. Development of potato late blight epidemics: Disease foci, disease gradients, and infection sources. Phytopathology 88:754-763.

Natural potato late blight epidemics were studied to assess the relative impact of various inoculum sources of Phytophthora infestans in Southern Flevoland (the Netherlands) from 1994 through 1996. Disease surveys were combined with characterization of isolates for mating type and DNA fingerprint pattern using probe RG57. Seventy-four percent of the commercial potato fields with early foci were clearly associated with nearby infested refuse piles. Characterization of isolates from refuse piles and fields confirmed the association. Infected seed tubers, volunteer plants, and infested allotment gardens appeared to be of minor importance for late blight development in potato fields. Several foci in refuse piles, potato fields, and allotment gardens contained more than one genotype. Due to
\end{abstract}

ABSTRACT favorable weather in August 1994, infested organic potato fields became major inoculum sources, resulting in the spread of $P$. infestans to adjacent conventional potato fields. Analyses of disease gradients, both at the field and regional levels, confirmed the role of the organic fields as mid-season infection sources. The mean slope of field gradients downwind of refuse piles (point sources) was significantly steeper (100-fold difference) than the mean slope of field gradients downwind of organic fields (area sources). The genotypic composition of the $P$. infestans populations along the gradient and of the source populations in the organic potato crops did not differ significantly. Analysis of the region gradient revealed genotypespecific disease gradients. Control measures are recommended.

Additional keywords: conventional potato growing, oospores, organic potato growing, overwintering.

ing in the soil after harvest and subsequent development of late blight on volunteer plants seemed of minor importance $(6,12,19)$.

In the early $1980 \mathrm{~s}$, there were indications that the P. infestans populations in Europe were changing. Isolates with the A2 mating type were detected in several European countries $(13,20)$. Migration of A1 and A2 genotypes from central Mexico to Europe in the 1970 s was demonstrated $(14,15)$. Populations of $P$. infestans have become increasingly diverse, and sexual reproduction now also occurs outside of Mexico $(9,25)$. Drenth et al. $(9,11)$ found the $P$. infestans population in the Netherlands to be highly diverse and concluded that sexual reproduction was the driving force behind the generation of new genotypes. In Dutch potato fields and allotment gardens with natural infections, oospores were encountered in leaves and tomato fruits (L. J. Turkensteen, personal communication). Drenth et al. (10) showed that oospores could survive in natural soil under Dutch winter conditions and could infect potato plants in the next season.

As a consequence of the changes, current late blight epidemics in the Netherlands might be different from those prior to the 1980s, both from a quantitative and a qualitative point of view. Oospores surviving in the soil could serve as an infection source in addition to tuber-borne inoculum. Genotypes of sexual origin might have increased pathogenic fitness, compared with old genotypes $(8,22)$, changing the rate at which epidemics develop.

A complicating factor concerns organic agriculture. Organic agriculture has been increasingly endorsed by the Dutch government (2). Since no fungicides are used on organic potato crops, high disease intensities may be found in these crops. Thus, infested organic potato crops might have a profound effect on spread and overwintering of the disease.

Prior to the 1980s, potato late blight epidemiology in the Netherlands was fairly well understood. The establishment of a new, sexually reproducing population requires reassessment of the relative 
impact of the various inoculum sources on epidemic development. Therefore, development of natural epidemics of $P$. infestans was studied from 1994 through 1996 in Southern Flevoland, one of the IJsselmeerpolders in the central part of the Netherlands. The aim of this paper is to analyze the development of potato late blight within and between various forms and locations of potato sites (i.e., refuse piles, volunteer plants, allotment gardens, and commercial fields), from the initial establishment of foci to the spread at a regional scale. We combined field observations with analysis of population structure using DNA fingerprinting with probe RG57 (16). Drenth et al. (11) found this probe to be a useful tool to identify genotypes during epidemic development in consecutive years.

\section{MATERIALS AND METHODS}

Selection of potato-growing area. Late blight epidemics were studied in a part of Southern Flevoland, the youngest polder in the Netherlands (Fig. 1), in 1994, 1995, and 1996. Land in this polder was reclaimed in the 1960s, and the first farms were established in the 1970s (soil type: marine clay). The research area (Fig. 2) was approximately 10 by $15 \mathrm{~km}$, including approximately 3,000 ha of ware and seed potatoes (mainly cultivar Bintje). This area included approximately 170 farms, of which 6 were organic and had approximately 140 ha of potatoes.

Reasons for choosing this specific area were (i) the occurrence of severe late blight epidemics in the early 1990s; (ii) an apparent conflict between conventional and organic potato growers about the role of infested organic potato fields with respect to late blight development in the region; (iii) the occurrence of relatively high densities of volunteer plants because tubers, left in the soil after harvest, survive easily in the young, well-aerated reclaimed soil (M. J. Zwankhuizen, unpublished data), which might have a profound effect on the development of late blight epidemics; and (iv) its distance (over $30 \mathrm{~km}$ ) from the nearest commercial potato-growing area located upwind, which reduces the probability of influx of inoculum.

Scouting for potato late blight. Field surveys were carried out by M. J. Zwankhuizen, in cooperation with officers of the Plant Protection Service and students of an agricultural college. In addition, growers and salesmen of the local pesticide suppliers were contacted frequently during the growing season. Our own findings, together with the information of local people, actual weather conditions, and weather forecasts determined the selection of fields to be inspected and the inspection frequency. The interval between inspection rounds varied from 1 week in periods favorable for late blight development to 2 or 3 weeks in dry periods.

The observational units were sites where potatoes grow. We distinguished four types of potato sites: refuse piles (R); fields with volunteer plants (V); commercial potato fields, either conventional (Fc) or organic (Fo) fields; and potato plots in allotment gardens (A). Potatoes in allotment gardens are grown by private citizens who hire an allotment situated within a large compound. Usually, no fungicides are applied in these gardens. Refuse piles and plots in allotment gardens were inspected completely. Fields with volunteer plants and commercial potato fields were inspected along two transects, one in each half of the field. A transect consisted of 10 potato rows, five to the left and five to the right of the observer, covering a width of $7.5 \mathrm{~m}$ over the full length of the field. On average, about $7.5 \%$ of the field area was inspected. In each compound of allotment gardens, 40 randomly selected plots (average size varied between 25 and $30 \mathrm{~m}^{2}$ ) were inspected per visit, which is approximately $22 \%$ of the area of potatoes per compound of allotment gardens (approximately $0.5 \mathrm{ha}$ ).

Inspections were most frequent in the Nz-section (the polder area has been subdivided into several sections to which codes are assigned; Fig. 2). The Nz-section was the area where the first organic farms of the region were established. In this area, severely infested organic potato fields led to discussions between growers.
The annual survey began by drawing a random sample of farms to be visited. In addition to these random samples, a selection of sites was visited more frequently, consisting of organic farms and infested potato sites and their immediate surroundings. We inspected at least $75 \%$ of the farms for refuse piles in the beginning of each season. At least 30 fields with volunteer plants and at least 30 commercial fields ( $10 \%$ of the total) were inspected each year to find early infections of late blight. An overview of the survey efforts made is given in Table 1.

Disease foci. A focus is a patch of crop with disease, limited in time and space (1). Disease intensity of foci in fields and allotment garden plots was determined by counting diseased stems, expressed as the number of diseased stems per square meter.

To determine whether a focus originated from an infected seed tuber (as described by Van der Zaag [27]), diseased plants within foci were thoroughly inspected and seed tubers of plants in the focus center were excavated to inspect them visually for $P$. infestans symptoms. Since the focus could have been initiated by soilborne oospores, $1 \mathrm{~kg}$ of soil was collected from its center and infectivity was determined using the bioassay described by Drenth et al. (10). Six foci from refuse piles, seven foci from potato fields, and three foci from allotment gardens were assayed.

Disease gradients. The change in disease intensity along a straight line from one point to another is termed a disease gradient (30). To study disease gradients, the distribution of late blight within commercial potato fields was determined using grid sampling. The rectangular sampling grid consisted of 16 plots of 15 or $30 \mathrm{~m}^{2}$ (four transects per field, with four plots along each transect). Early in the season, disease intensity was determined as the fraction of plants diseased per sampling plot of $15 \mathrm{~m}^{2}$. Later in the season, it was difficult to distinguish separate plants, so late blight intensities were determined by counting leaf and stem lesions per plot of $30 \mathrm{~m}^{2}$.

Downwind disease gradients were constructed by using the distance from the probable source to every plot of the sampling grid

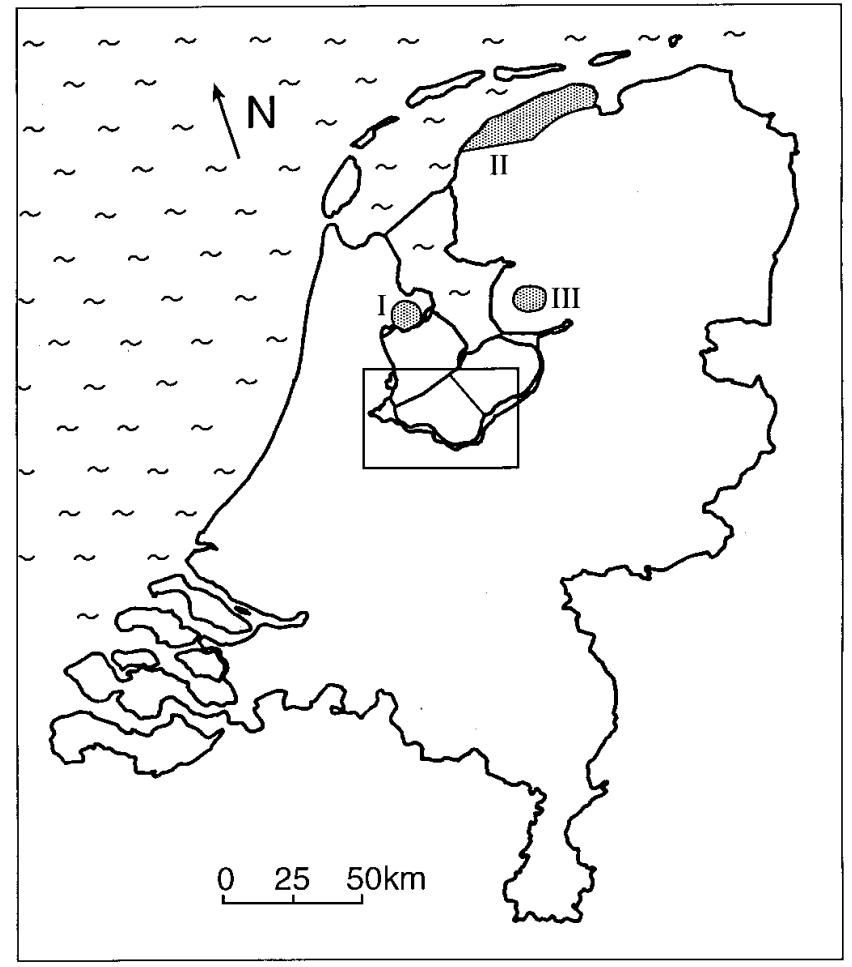

Fig. 1. The Netherlands. Potato late blight epidemics were studied in Southern Flevoland (indicated by a rectangle) in 1994, 1995, and 1996. Earlier studies on late blight epidemics were carried out in areas I (De Streek) from 1952 to 1955 (27), II (Friesland) in 1965 (J. C. Zadoks and H. Lohuis, unpublished data), and III (Noordoostpolder) in 1968 (J. C. Zadoks and L. C. Davidse, unpublished data). Results of these studies are used in this paper. 
within the field and the disease intensity in the sampled plot. Due to frequent fungicide applications, disease intensities near infested refuse piles were generally low. Therefore, data of only one field from our study could be used in the disease gradient analysis, and data from fields near refuse piles studied previously and elsewhere in the Netherlands were included (Fig. 1).

To describe the spread of late blight from the organic fields to the conventional fields, the probable source was represented by a virtual source (Fig. 3), calculated by averaging the coordinates of a group of closely located organic fields. Within-field gradients and one among-fields gradient (further referred to as the region gradient) were constructed. Representative conventional fields along the region gradient were selected based on their relative positions to the organic fields and their disease levels. The region gradient was constructed using the data of downwind fields Fc5, Fc6, Fc7, $\mathrm{Fc} 8, \mathrm{Fc} 9, \mathrm{Fc} 10$, and Fc11. A crosswind disease gradient at 1,306 m downwind from the virtual source was constructed using disease intensities measured in conventional fields Fc5, Fc6, Fc8, and Fc11. The genotypic composition of the $P$. infestans population along the region gradient was determined.

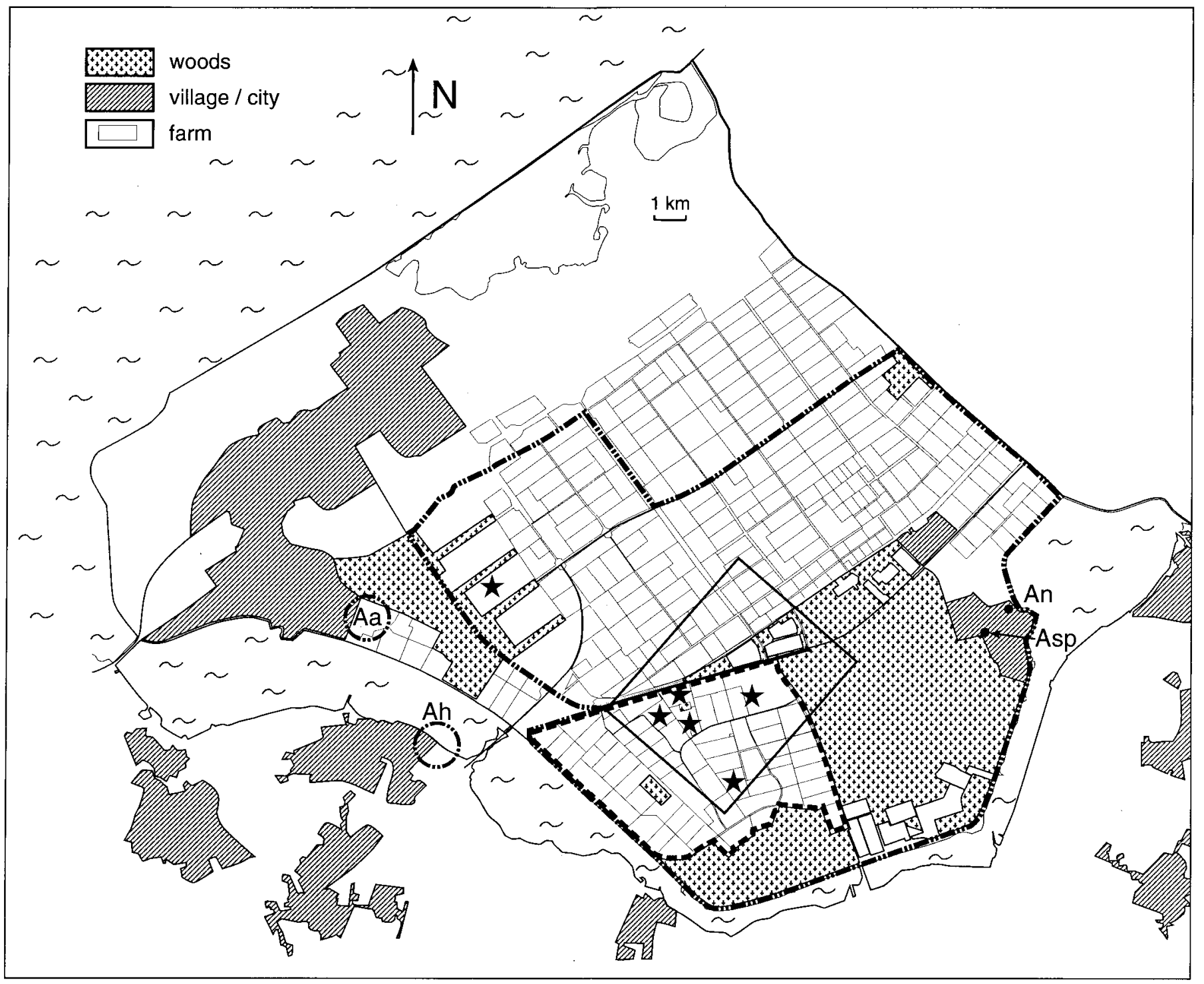

Fig. 2. Southern Flevoland and adjacent areas. The research area (-.......), the Nz-section (---), the location of compounds of allotment gardens (Aa, Ah, An, and Asp), and organic farms $(\star)$ are indicated. The rectangle indicates the area in which spread of late blight from organic fields to conventional fields was studied (shown in detail in Fig. 3).

TABLE 1. Numbers of inspected potato sites and numbers of infested potato sites found (in parentheses) ${ }^{\mathrm{a}}$

\begin{tabular}{|c|c|c|c|c|c|}
\hline \multirow[b]{2}{*}{ Year } & \multirow[b]{2}{*}{ Refuse piles } & \multicolumn{3}{|c|}{ Potato site } & \multirow[b]{2}{*}{ Total } \\
\hline & & Fields with volunteer plants & Potato fields, conventional and organic & Allotment gardens & \\
\hline 1994 & $63(9)$ & $29(1)$ & $145(33)$ & $760(70)^{\mathrm{b}}$ & 997 (113) \\
\hline 1995 & $129(2)$ & $36(0)$ & $59(20)$ & $720(45)$ & $944(67)$ \\
\hline Total & $283(11)$ & $73(1)$ & $336(62)$ & $3,360(150)$ & $4,052(224)$ \\
\hline
\end{tabular}

a Total number of infested potato sites found in the research area (including those found by others) was only slightly more, except for the potato fields in 1994 . In that year, more than $90 \%$ of all commercial potato fields in the research area was infested in June, so the total number of infested fields in 1994 was much higher than the number of fields recorded by us. Many potato sites were inspected more than once.

${ }^{b}$ Minimum number of infested potato plots encountered in compounds of allotment gardens. 
Collection of isolates. Isolates were collected in several ways. In small foci ( $<30$ diseased plants), 10 single lesion samples, and in large foci ( $\geq 30$ diseased plants), 30 single lesion samples were obtained from separate plants scattered along the downwind and crosswind axes of the focus.

From the infested organic fields, 30 isolates were collected randomly along two transects. From conventional fields, located downwind of organic fields, in which late blight intensity was determined using grid sampling, one isolate per grid point was collected when possible. From other conventional fields near the organic fields, 5 to 10 isolates were collected randomly along the disease gradient. If no disease gradient was visible, isolates were collected randomly along two transects. Formal sampling requirements could not always be satisfied, e.g., due to the fact that growers had already started to remove diseased plants or because of contaminations and loss of isolates during culturing.

Individual isolates were obtained from single lesions on stems or leaves according to the method of Davidse et al. (7). Pure cultures were obtained by plating the mycelium on rye A medium (5) amended with antibiotics. Pure cultures were kept on rye A medium at $18^{\circ} \mathrm{C}$ in the dark or stored in liquid nitrogen.

Characterization of isolates. All isolates were characterized for mating type and RG57 fingerprint pattern (16). To assess mating type, isolates were grown on clarified rye A agar medium in prox- imity to a strain of known mating type (A1 or A2). Each isolate was tested against a known A1 strain and a known A2 strain. Oospore formation usually was recorded after 1 week.

For DNA fingerprinting, isolates were grown in liquid rye A medium in the dark at $18^{\circ} \mathrm{C}$ for approximately 3 weeks. Mycelium was harvested and stored at $-80^{\circ} \mathrm{C}$ for further use. DNA isolation, EcoRI digestion, Southern blotting, and hybridization with probe RG57 were performed as described by Drenth et al. (9).

A multilocus genotype was constructed for each isolate by combining data for mating type and DNA fingerprint loci $(17,25)$. A genotype was designated unique if one or more isolates of this genotype were detected only in one sampling site in the research area (from 1993 through 1996).

Source-target relations. A source (or an infection source) is defined as a plant or a group of plants within a potato site with sporulating lesions from which spores are dispersed. A target is defined as a plant or group of plants within a potato site on which spores, originating from the source, are deposited, resulting in diseased tissue.

To determine whether an infested potato site had acted as an infection source for another potato site (the target), two items were considered: the disease gradient and the genotypic composition of source and target. If disease intensity in the target potato site is high enough, a disease gradient can be determined (18). A primary

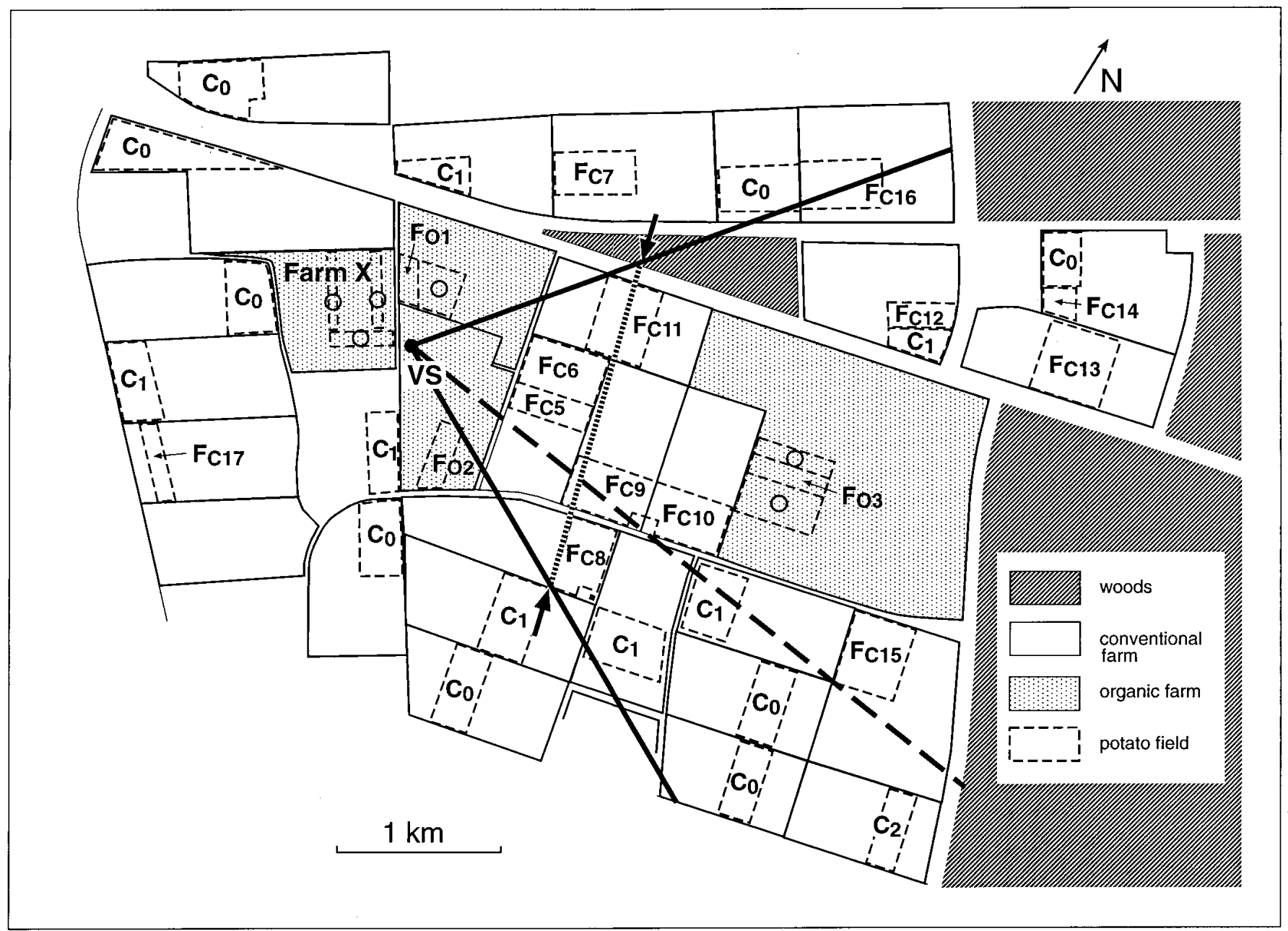

Fig. 3. Conventional and organic potato fields in Southern Flevoland in the summer of 1994. The cone of dispersal from the virtual source (VS; described in text), its calculated bisector, and the approximate position of the crosswind gradient (arrows) are indicated. Grid sampling for gradient analysis was applied in fields Fc5, 6, 7, 8, 9, 10,11, and 12. Isolates for characterization were collected in all potato fields indicated with Fc and Fo. No late blight was found during inspections between 31 August (day 243) and 21 September (day 264) in conventional fields indicated with $\mathrm{C}_{0}$. Conventional fields indicated with $\mathrm{C}_{1}$ were not sampled; disease intensities were very low (one to four lesions per field) between 31 August (day 243) and 21 September (day 264). Conventional field $\mathrm{C}_{2}$ was severely infested in the last week of August, but canopy was destroyed before sampling. Other organic fields (O) were infested in the last decade of August, but no isolates could be collected because of rapid haulm killing. 
disease gradient consists of all first-generation infections coming from the source under consideration (30), suggesting a source-target relation with decreasing disease intensities at increasing distance from the source. If late blight in a given target originates from a given source, the genotypic compositions of source and target populations must match (29).

Statistical analyses. Disease gradients were analyzed by nonlinear regression using the exponential model of Kiyosawa and Shiyomi (23), $y=a e^{-b x}$, in which $y$ is the disease intensity at distance $x, a$ is the $y$ intercept, and $b$ is the slope of the gradient. Slope $(b), y$ intercept $(a)$, coefficient of determination $\left(R^{2}\right)$, and significance of the regression $(P)$ were estimated. Data of the crosswind disease gradient were fitted to a Gaussian model $\left(y=a_{0}+a_{1}\right.$ $\left.\exp \left\{-0.5\left[\left(x-a_{2}\right) / a_{3}\right]^{2}\right\}\right)$ using nonlinear regression.

Slopes of field gradients downwind of refuse piles and slopes of field gradients downwind of organic fields (from significant regressions) were compared using the nonparametric Mann-Whitney $U$ test (24).

Chi-square tests were conducted to identify differences in genotype frequencies encountered in target fields and their respective sources.

\section{RESULTS}

Late blight epidemics in 1994, 1995, and 1996. Late blight epidemics differed dramatically from each other with regard to the date of first appearance of late blight, the overall disease level, and the development pattern during the growing season (Table 2). The pattern of disease development during the growing seasons was quite similar to the pattern of alternating periods with favorable and unfavorable weather conditions. The distribution of the total precipitation over the course of the growing season of 1994, 1995, and 1996 is an example (Fig. 4). The number of days from May through September with precipitation were 67, 66, and 67, respectively, whereas the total amounts of precipitation during those periods were 448, 347, and $239 \mathrm{~mm}$, respectively, for the different years.

1994. During the surveys from April through June, 93 farms were visited. Of 62 refuse piles found, 52 (84\%) were not covered or were incompletely covered by plastic foil. On nine of these refuse piles $(17 \%)$, diseased plants were found. Five of the infested refuse piles were encountered in the Nz-section (Fig 2). Conditions were favorable for late blight development until the third week of June. Around mid-June, $P$. infestans was present in most potato fields. Due to hot and dry weather in July, disease intensities decreased, and almost no newly infested potato sites were found. After this dry period, weather conditions again were favorable for late blight, and actively sporulating foliar lesions were found in organic field Fo1 on 16 August (Julian day 228) (Fig. 3). The foliage in this field was killed by flaming 1 day after our visit on 19 August (day 231). On 25 and 26 August (days 237 and 238), the organic growers began to destroy the foliage of their severely diseased crops (disease intensities 100 to 250 lesions per $30 \mathrm{~m}^{2}$ ). From 26 August (day 238), disease began to appear in the conventional fields

TABLE 2. Development ${ }^{\mathrm{a}}$ of late blight in Southern Flevoland during the growing seasons of 1994 through 1996

\begin{tabular}{lcrccc}
\hline Year & May & June & July & August & September \\
\hline 1994 & + & ++++ & - & $++^{\mathrm{b}}$ & $+^{\mathrm{b}}$ \\
1995 & 0 & ++ & + & $+-^{\mathrm{b}}$ & $-^{\mathrm{b}}$ \\
1996 & 0 & 0 & + & + - $^{\mathrm{b}}$ & $+/-^{\mathrm{b}}$ \\
\hline
\end{tabular}

a $0=$ no late blight observed; $-=$ decrease of disease intensity due to hot, dry weather; $+/-=$ only very slight increase of disease intensity and number of infested potato sites; $+=$ few potato sites infested, slight increase of disease intensity; $++=1$ to $10 \%$ of potato sites infested, moderate increase of disease intensity and number of infested potato sites; and $++++=>90 \%$ of potato sites infested and rapid increase of disease intensity.

b Decrease in number of infested potato sites due to vine killing on organic and conventional fields. located downwind (east) of the organic fields (Fig. 3). Far less disease was found in conventional fields in the upwind direction. $P$. infestans was recorded in allotment gardens from the beginning of July until the beginning of August. Disease developed slowly due to hot and dry weather in this period.

1995. Weather conditions were more or less favorable for late blight development until the first half of July (Fig. 4). During the rest of the growing season (until the third week of September), weather was almost continuously unfavorable. Of 124 refuse piles identified on 139 farms, 65 (52\%) were not covered or were incompletely covered by plastic foil. Only two diseased refuse piles were encountered, $3 \%$ of the incorrectly covered piles. Early disease foci in commercial fields were found 17 days later than in 1994 (day 171). No disease spread from the organic fields to the conventional fields was observed, despite high disease intensities (comparable to 1994) in most of the organic fields at the end of July. After mid-July, disease development was limited due to hot and dry weather. In allotment gardens, disease was found from the last week of June till the end of the growing season, but disease progressed slowly and never reached high levels.

1996. Seventy-nine refuse piles located at 135 farms were inspected. Even though $58 \%$ of the refuse piles were not covered or were incompletely covered, no diseased plants were found. Weather was unfavorable for late blight until the second half of July (Fig. 4). Thereafter, weather conditions were rather unstable, sometimes being favorable and sometimes not. Disease in the area was first found in an organic field on 24 August (day 206), 88 and 42 days later than in 1994 and 1995, respectively. The organic fields were the only potato fields where late blight was found until mid-September. Only very late in the growing season, when many growers already had started haulm killing, were some lesions found in a few conventional fields. Initially, disease developed slowly in the allotment gardens after the first detection on 31 July (day 213), but at the end of August, when most potatoes were harvested, nearly all tomato plots were found to be infested.

In 1994 and 1996, densities of volunteer plants were low $(\leq 1,000$ plants per ha). In 1995, average density was approximately 5,500 volunteer plants per ha. No significant disease development was recorded in fields with volunteer plants throughout the three growing seasons.

Disease foci. Typical foci of $P$. infestans (27) in refuse piles were difficult to recognize because of the use of herbicides and mechanical disturbance. Six distinct foci were identified in three refuse piles (Table 3). In all infested refuse piles, including those without typical foci, many rotten tubers were found, some with symptoms of $P$. infestans. Symptoms were visible on both below-ground and above-ground stem parts, and foci appeared to have developed from infected tubers. Only two foci were genotypically uniform (Table 3), indicating that several independent infections occurred, even within small foci consisting of only three to seven diseased stems. Most isolates $(91 \%)$ collected on refuse piles in 1994 and 1995, includ-

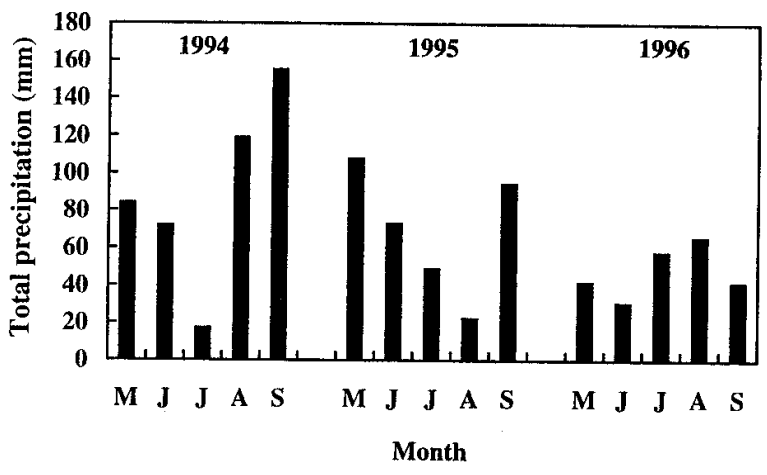

Fig. 4. Total precipitation in May (M), June (J), July (J), August (A), and September (S) of 1994, 1995, and 1996. Data from the Royal Netherlands Meteorological Institute (KNMI) at De Bilt, located $20 \mathrm{~km}$ south of the research area. 
ing those without typical foci, belonged to predominant genotypes NL-41, NL-69, NL-75, and NL-76.

During the 3 years of the study, 34 early foci were found in 20 potato fields and were inspected thoroughly. In 1994 and 1995, these foci were encountered from the first week of June through the first week of July. In 1996, only one focus was found in an organic field on 24 July (day 206), the first disease record of that year in the research area. In general, a focus (disease intensity ranging from less than 5 to 100 diseased plants) consisted of one severely diseased plant with reduced growth, all stems blighted, and nearly all leaflets infected. Surrounding plants had one to three diseased stems, with $10 \%$ of the leaflets diseased. Plants outside the focal center generally had one diseased stem, with one leaf or stem lesion. Symptoms on below-ground stem parts were never found in foci in potato fields. In only a few cases, the planted seed tubers were slightly infected with $P$. infestans. A selection was made for the characterization of foci from potato fields (Table 3). Six foci from three fields in 1994 represented the foci encountered during the early outbreak of late blight: the four foci in fields Fc1 and Fc2 were the first detected foci in the research area in 1994; the two foci in field Fc4 were selected because the field was located downwind of field Fc3 and refuse pile Rc2, and the question was whether disease in this field could have originated from refuse pile Rc2. The two foci characterized in 1995 were the first foci found in the area early in the season in that year. No other foci were found to be appropriate for characterization, either because foci were found too late or because they had been (partially) removed by the grower. The only focus found in 1996 was selected for DNA fingerprinting. Seven foci, found in 1994 and 1995, were each genotypically uniform and contained the predominant genotype NL-41 or NL-75. One focus in field Fc4 in 1994 had two genotypes, probably resulting from the simultaneous establishment of at least two infections from source Rc2, with isolates belonging to genotypes NL-41 and NL-75. The focus on field Fo1, found in 1996, contained two unique genotypes. In this field, six genotypes were detected in total, five of which were unique or rare (M. J. Zwankhuizen, T. van der Lee, F. Govers, and J. C. Zadoks, unpublished data).

In allotment gardens, disease levels were generally low. Disease usually began with a few infected leaves, scattered over the plot; the typical focal pattern of disease described for the commercial fields was rarely evident. Out of 41 potato sites sampled in allotment gardens from 1994 through 1996, only three typical foci were found and characterized (Table 3). The structure of these foci was quite similar to those described for the commercial potato fields. Two foci appeared to be genotypically uniform, but one focus had isolates belonging to four (unique) genotypes. In the latter case, almost all plants in the plot were infected.

Soil samples collected in foci from refuse piles, potato fields, and allotment gardens were not infectious, according to the bioassay.

Disease gradients. Disease intensity in commercial potato fields near infested refuse piles was generally low due to frequent fungicide applications. Data from only one field of our study ( $\mathrm{Fc} 3$ near refuse pile $\mathrm{Rc} 2$ ) were included in the disease gradient analysis.

In September 1994, disease was assessed and isolates were collected in most of the infested conventional fields located downwind (east) of the organic fields (Fig. 3). To analyze the spread of disease over the region, organic potato fields Fo1, Fo2, and the potato fields on farm $\mathrm{X}$ were used to construct the virtual source (VS). Although no inspections were done on farm $\mathrm{X}$ (this grower did not cooperate), we assume that disease intensity on this farm was as high as on Fo1 and Fo2, in accordance with reports of neighbors who had visited this farm. The region gradient was visible as a sector with its origin in the virtual source. Seventeen conventional fields located upwind of the organic fields were inspected between 31 August (day 243) and 21 September (day 264) (seven of these fields were visited twice). Disease was detected in only three upwind fields, and only the disease intensity of field $\mathrm{Fc} 17$ was relatively high (10 lesions per $30 \mathrm{~m}^{2}$ ) (Fig. 3).

TABLE 3. Characteristics of foci of Phytophthora infestans found in Southern Flevoland in 1994, 1995, and 1996

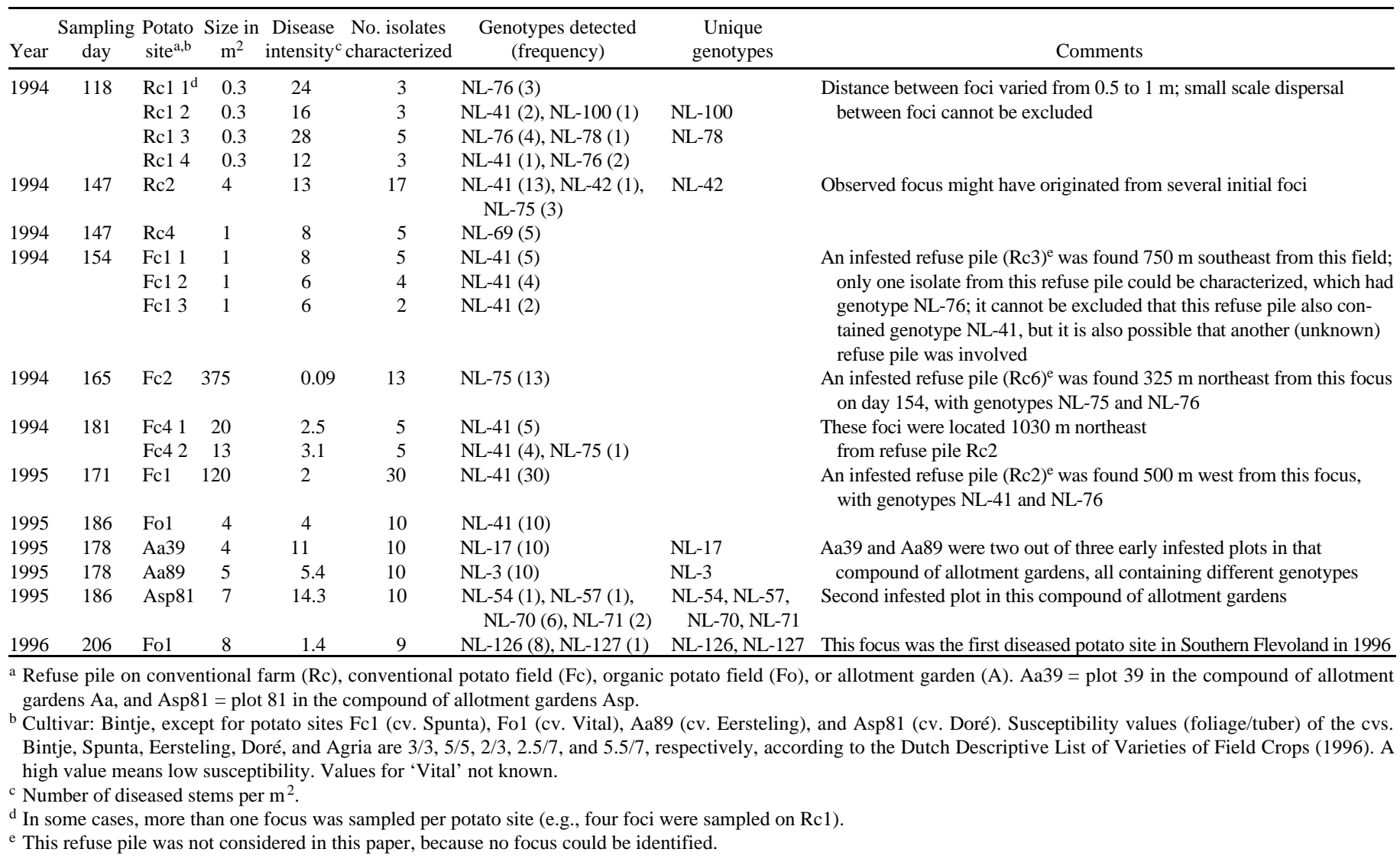


Slopes of the field gradients downwind of the refuse piles varied considerably, whereas slopes of the field gradients downwind of the organic fields were all in the same order of magnitude, despite differences in disease intensity (Table 4). For field Fc3, the exponential model gave a poor fit. The mean slope of the field gradients downwind of the refuse piles and the mean slope of the field gradients downwind of organic fields were -0.35 and $-0.0045 \mathrm{~m}^{-1}$, respectively (Table 4$)$. This 100 -fold difference is statistically significant $(P<0.01)$.

The slope of the region gradient (Fig. 5A) and the mean slope of its individual field gradients were in the same order of magnitude $\left(-0.0029\right.$ and $-0.0045 \mathrm{~m}^{-1}$, respectively) (Table 4$)$. The crosswind gradient (Fig. 5B) was described by the simplified Gaussian equation: $y=0.78+8.24 \exp \left(-0.5[x / 211.14]^{2}\right)\left(R^{2}=0.70, P<\right.$ 0.001 ), with the bisector of the cone pointing to the east (Fig. 3 ).

Results of the characterization of isolates revealed remarkable differences between disease gradients of genotypes NL-41 and NL-76 in the $y$ intercept and the slope of the gradient (Table 4, Fig. 5C and D).

Source-target relations. An infested refuse pile was found at a median distance of $600 \mathrm{~m}$, with $50 \%$ of the distances between 160 and $900 \mathrm{~m}$, for 14 out of 19 potato fields (74\%) in which early foci were studied in 1994 and 1995. An infested refuse pile appeared the most likely infection source for seven out of nine foci in potato fields from which isolates were characterized (Table 3 ). Most isolates from refuse pile Rc2 and from downwind fields $\mathrm{Fc} 3$ and Fc4 belonged to the predominant genotypes NL-41 and NL-75 (94 and 97\%, respectively). No significant disease gradient was present in field $\mathrm{Fc} 3$, but genotypic compositions of the target pop- ulations in fields $\mathrm{Fc} 3$ and $\mathrm{Fc} 4$ and the putative source population of refuse pile Rc2 did not differ significantly $(P=0.88)$ (Table 5). The result of this test may be unreliable because $50 \%$ of the expected values were lower than 5 . When only the predominant genotypes NL-41 and NL-76 were considered, there was no difference in genotypic composition according to Fisher's exact test $(P=0.62)(24)$.

Field gradients and the region gradient suggested organic fields Fo1, Fo2, and the fields on organic farm X to have been the infection sources for nearby conventional fields in 1994 (Table 4). Three organic fields (Fo1, Fo2, and Fo3, with moderately resistant cvs. Provento, Santé, and Escort, respectively) (Fig. 3) could be sampled just before growers destroyed the foliage by flaming. Most isolates of fields Fo1 and Fo2 (80\%) belonged to genotypes NL-41 and NL-76. The majority of isolates (89\%) collected in conventional fields located downwind and upwind also belonged to genotypes NL-41 and NL-76. Genotypic compositions of source and target populations were not significantly different $(P=0.11)$ (Table $6)$. Field Fo3 appeared not to have acted as a source. All 14 isolates from this field had genotype NL-48, and this genotype was not found in any other field.

The relative importance of organic fields Fo1 and Fo2 might be different for different conventional fields, according to the results of disease gradient analysis and the isolate characterizations. If real sources are used instead of the virtual source, regressions gave a better fit for some fields (for target Fc7 and source Fo2, $R^{2}=0.48$, $P<0.01$; for targets Fc8, Fc9, and Fc11 and source Fo1, $R^{2}=$ $0.28,0.44$, and 0.31 , and $P<0.01,0.01$, and 0.05 , respectively). The rare genotype NL-77 was found for the first time in Fol and

TABLE 4. Disease gradients of Phytophthora infestans in potato fields downwind of refuse piles (in Southern Flevoland in 1994, in Friesland in 1965, and in Noordoostpolder in 1968) and in fields downwind of organic fields in Southern Flevoland in 1994

\begin{tabular}{|c|c|c|c|c|c|c|c|c|c|c|}
\hline Field - probable source ${ }^{a}$ & Year & $\begin{array}{l}\text { Disease } \\
\text { intensity }^{\mathrm{b}}\end{array}$ & $\begin{array}{c}\text { Day of first late } \\
\text { blight observation }\end{array}$ & $\begin{array}{c}\text { Day of } \\
\text { sampling }\end{array}$ & $\begin{array}{l}\text { Distance to } \\
\text { source }(\mathrm{m})^{\mathrm{c}}\end{array}$ & $n^{\mathrm{d}}$ & $\begin{array}{c}y \text { Intercept } \\
(a)^{\mathrm{e}}\end{array}$ & $\begin{array}{l}\text { Slope }(b) \\
\left(\mathrm{m}^{-1}\right)^{\mathrm{e}, \mathrm{f}}\end{array}$ & $R^{2 \mathrm{~g}}$ & $\begin{array}{c}\text { Significance } \\
(P)\end{array}$ \\
\hline \multicolumn{11}{|l|}{ Field gradients } \\
\hline Fcr1 - Rc007 & 1965 & 3.3 & 183 & 183 & 34 & 30 & 6.6 & -0.033 & 0.53 & $<0.001$ \\
\hline Fcr2 - Rc007 & 1965 & 0.8 & 183 & 183 & 59 & 30 & 1.0 & -0.016 & 0.15 & $<0.05$ \\
\hline Fca - Rc058 & 1965 & 1.9 & 189 & 189 & 70 & 13 & 7.3 & -0.051 & 0.86 & $<0.001$ \\
\hline Fch - Rc109 & 1965 & 1.9 & 174 & 174 & 30 & 4 & 6.8 & -0.30 & 0.97 & $<0.05$ \\
\hline Fcb - Rc1 & 1965 & 1.5 & 161 & 172 & 15 & 25 & 60.3 & -1.35 & 0.71 & $<0.001$ \\
\hline Fco - Rc107 & 1968 & 0.2 & 164 & 164 & 155 & 8 & 0.4 & -0.0078 & 0.76 & 0.46 \\
\hline $\mathrm{Fc} 3-\mathrm{Rc} 2$ & 1994 & 0.2 & 167 & 168 & 365 & 16 & 0.33 & -0.0025 & 0.15 & 0.14 \\
\hline Fc7 - VS & 1994 & 15.3 & 243 & 244 & 1,570 & 16 & 29.3 & -0.0036 & 0.25 & $<0.05$ \\
\hline Fc11 - VS & 1994 & 1.7 & 241 & 244 & 1,335 & 16 & 3.2 & -0.0035 & 0.14 & 0.16 \\
\hline Fc6 - VS & 1994 & 2.1 & 238 & 244 & 973 & 16 & 5.6 & -0.0074 & 0.67 & $<0.001$ \\
\hline Fc5 - VS & 1994 & 10.2 & 238 & 244 & 950 & 16 & 19.4 & -0.0044 & 0.83 & $<0.001$ \\
\hline Fc8 - VS & 1994 & 1.7 & 243 & 250 & 1,660 & 14 & 4.9 & -0.0076 & 0.20 & 0.11 \\
\hline Fc9 - VS & 1994 & 5.1 & 239 & 244 & 1,508 & 15 & 8.1 & -0.0027 & 0.35 & $<0.05$ \\
\hline Fc12 - VS & 1994 & 32.1 & 242 & 250 & 3,140 & 15 & 53.8 & -0.0046 & 0.39 & $<0.01$ \\
\hline \multicolumn{11}{|l|}{ Region gradients } \\
\hline Region $^{\text {h }}$ - VS & 1994 & 3.5 & $\ldots^{\mathrm{i}}$ & $\ldots$ & $\ldots$ & 92 & 11.5 & -0.0029 & 0.44 & $<0.001$ \\
\hline Region $41+76^{j}-V S$ & 1994 & 3.7 & $\ldots$ & $\ldots$ & $\ldots$ & 52 & 11.5 & -0.0017 & 0.41 & $<0.001$ \\
\hline Region $41^{\mathrm{j}}-\mathrm{VS}$ & 1994 & 4.5 & $\ldots$ & $\ldots$ & $\ldots$ & 13 & 20.0 & -0.0050 & 0.98 & $<0.001$ \\
\hline Region $76^{\mathrm{j}}-\mathrm{VS}$ & 1994 & 3.7 & $\ldots$ & $\ldots$ & $\ldots$ & 39 & 6.3 & -0.00059 & 0.18 & $<0.01$ \\
\hline
\end{tabular}

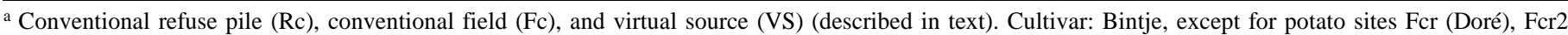
(Eigenheimer), Fco (Sirtema), and Fc6 (Marijke). Susceptibility values (foliage/tuber) of the cvs. Bintje, Doré, Eigenheimer, Sirtema, and Marijke are 3/3, 2.5/7, 4.5/3, 2/6, and 5/4, respectively, according to the Dutch Descriptive List of Varieties of Field Crops (1996). A high value means low susceptibility.

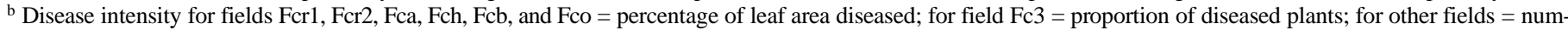
ber of lesions per $30 \mathrm{~m}^{2}$. For Fc10 (Fig. 3), no disease was found at any grid point; only one isolate could be found near the edge of the field. For fields Fc13, 14, 15, 16, and 17 (Fig. 3), no grid sampling was applied, but disease intensities, estimated during collection of isolates, were 1.8, 0.0, 0.0, 1.0, and 10.0, respectively.

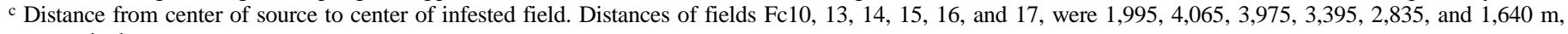
respectively.

d Number of observation points (grid or line sampling).

e Determined by nonlinear regression of the data to the model $y=a e^{-b x}$

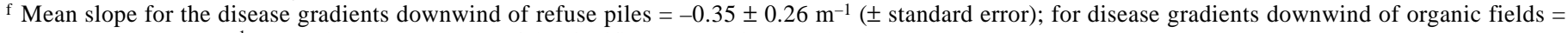
$-0.0045 \pm 0.00079 \mathrm{~m}^{-1}$ ( \pm standard error); slopes of the significant regressions used only.

g Coefficient of determination.

${ }^{\mathrm{h}}$ Gradient over fields Fc5, 6, 8, 9, 10, and 11. Selection of fields described in text.

${ }^{\mathrm{i}}$ Described in field data.

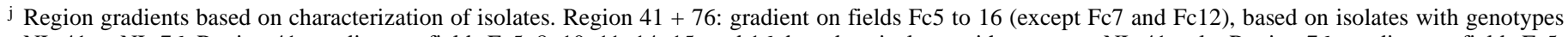
NL-41 or NL-76. Region 41: gradient on fields Fc5, 8, 10, 11, 14, 15, and 16, based on isolates with genotype NL-41 only. Region 76: gradient on fields Fc5, $6,8,9,11,13,14$, and 16 , based on isolates with genotype NL-76 only. 
later in downwind field $\mathrm{Fc} 12$, indicating that $\mathrm{Fo} 2$ was the most important source for $\mathrm{Fc} 12$.

\section{DISCUSSION}

Muddy epidemics. Waggoner's (28) statement "we shall find the real epidemic muddy and uncomfortable" is certainly applicable to our subject. Late blight epidemics differed dramatically between years due to weather conditions. Several other confounding factors such as differences in spray regime, crop growth, and removal of diseased plants by growers resulted in variation of disease development among fields. The statistical design was far from unbiased. Fields were not always selected randomly for inspection and sampling, and isolates could not always be sampled at random within potato sites. The system under study was also influenced by the

TABLE 5. Numbers of isolates belonging to genotypes NL-41, NL-75, and others found in refuse pile Rc2 and fields Fc3 and Fc4 in Southern Flevoland, 1994

\begin{tabular}{lcccc}
\hline & \multicolumn{3}{c}{ Genotypes } & \\
\cline { 2 - 4 } Potato site & NL-41 & NL-75 & Others & Total \\
\hline Refuse pile Rc2 & 14 & 3 & 1 & 18 \\
Conventional fields Fc3 ${ }^{\text {b }}$ and Fc4 & 29 & 6 & 1 & 36 \\
Total & 43 & 9 & 2 & 54 \\
\hline
\end{tabular}

${ }^{a}$ Genotypic composition of the population in refuse pile and fields not significantly different $(P=0.88)$ according to the chi-square test. $P$ value may be inaccurate because three expected values were $<5$.

${ }^{\mathrm{b}}$ In this field, 30 isolates were collected along five transects.
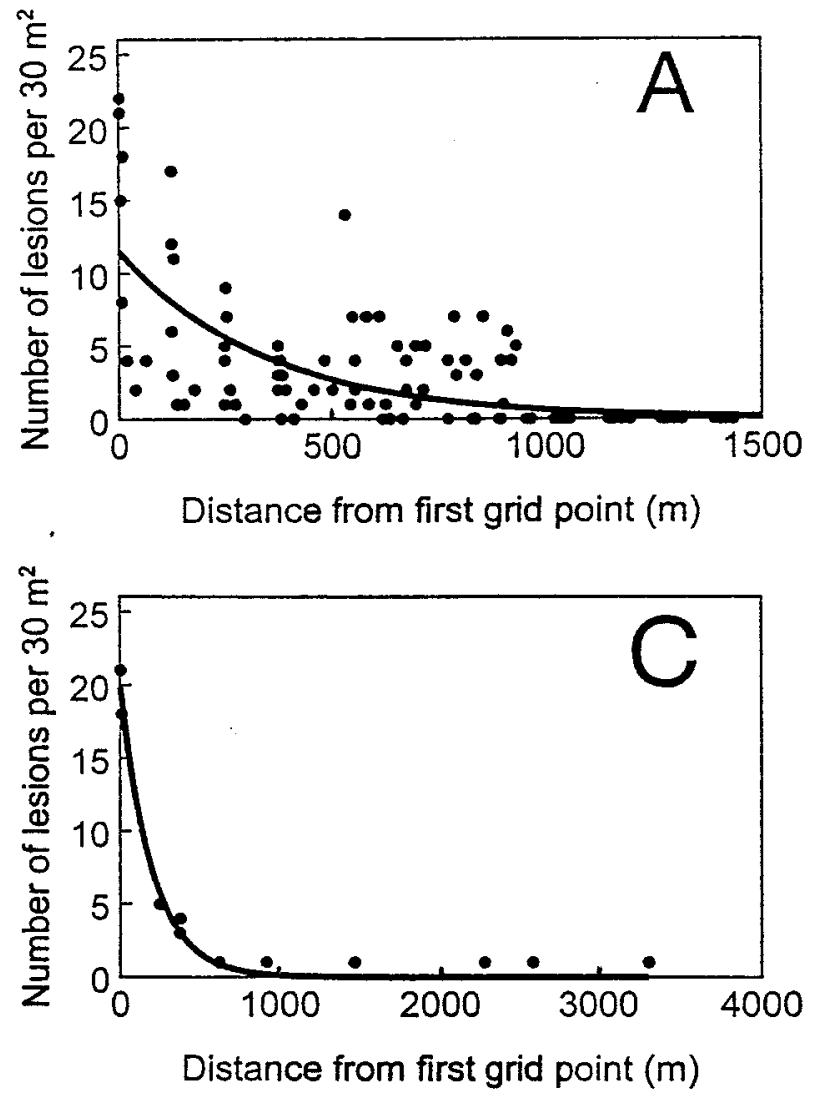

researcher. Frequent inspections alerted growers, reducing the representativeness of the results. The inconvenience of a strong bias in the sample surveys had to be accepted in view of the inevitable mix of research questions. Notwithstanding these objections, fieldoriented research is essential to obtain a true understanding of the survival and spread of the late blight fungus $P$. infestans. We tried to overcome the methodological problems by selecting representative potato sites for the analysis.

Disease foci. Foci on refuse piles had a similar structure as the foci described by Van der Zaag (27) and appeared to have originated from infected tubers. Foci encountered in potato fields did not include plants that could have originated from infected seed tubers, according to the description of Van der Zaag (27). In a few cases, diseased seed tubers were found, but they were only slightly infected. It is likely that these tubers were infected by spores washed down from infected leaves and stems. Experiments are needed to test this hypothesis. In allotment gardens, the focal pattern of dis-

TABLE 6. Numbers of isolates belonging to genotypes NL-41, NL-76, and others found in organic fields Fo1 and Fo2 and downwind conventional fields (Fc5 to 16) in Southern Flevoland, 1994 ${ }^{\mathrm{a}}$

\begin{tabular}{lcccc}
\hline & \multicolumn{3}{c}{ Genotypes } & \\
\cline { 2 - 4 } Potato site & NL-41 & NL-76 & Others & Total \\
\hline Organic fields Fo1 and Fo2 & 3 & 21 & 6 & 30 \\
Conventional fields Fc5 to 16 & 22 & 48 & 9 & 79 \\
Total & 25 & 69 & 15 & 109 \\
\hline
\end{tabular}

a Genotypic composition of the population in organic and conventional fields not significantly different $(P=0.11)$, according to the chi-square test.
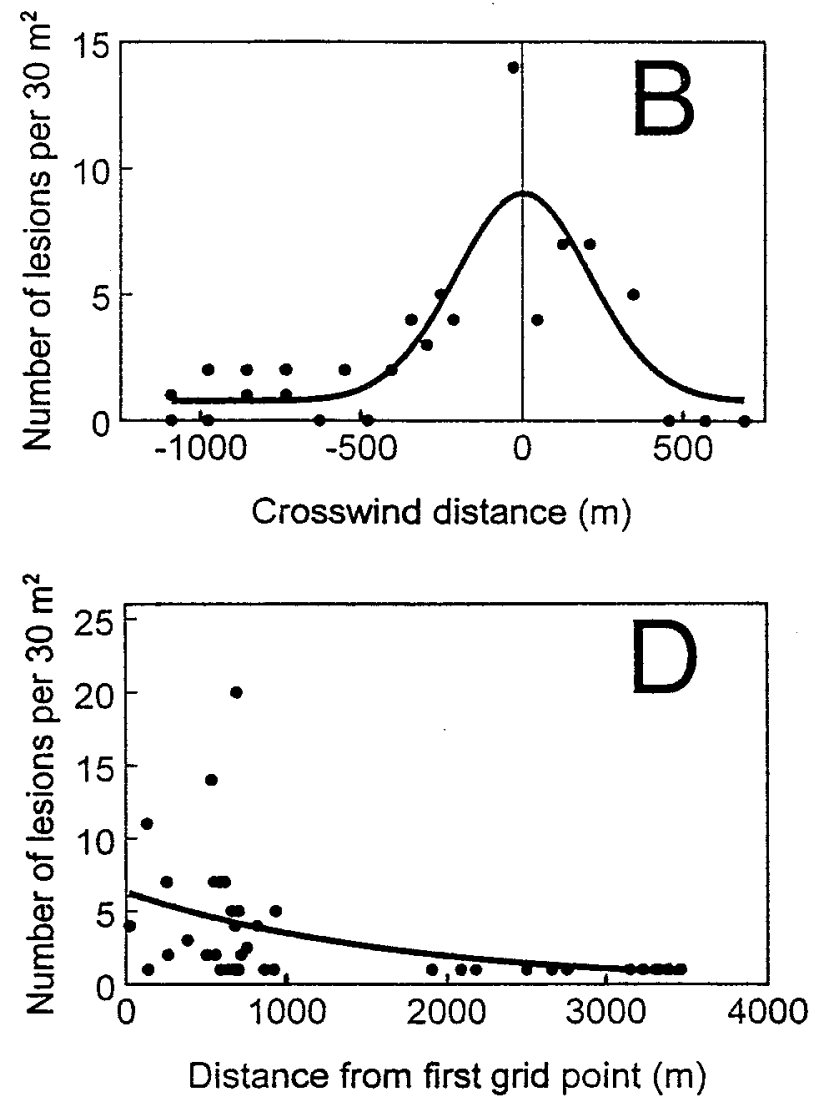

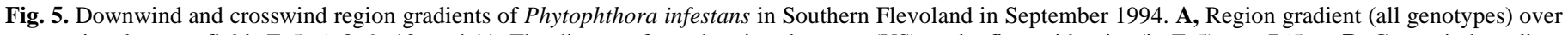

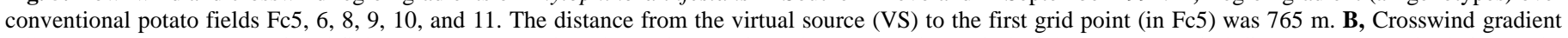

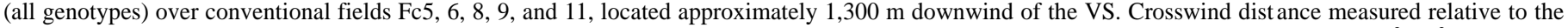

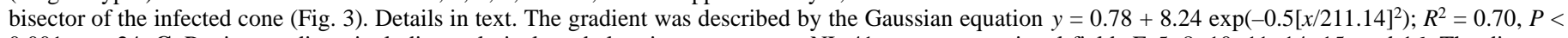

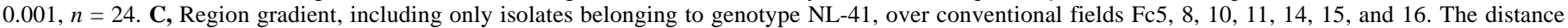

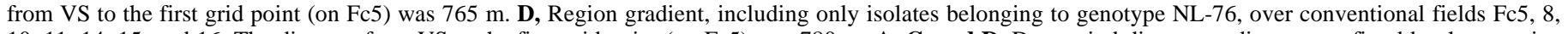

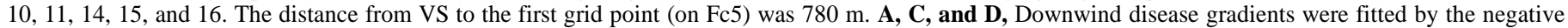
exponential model $\left(y=a e^{-b x}\right)$; the parameters are given in Table 6 . 
ease was usually not evident, probably because most infections resulted from oospores (M. J. Zwankhuizen, T. van der Lee, F. Govers, and J. C. Zadoks, unpublished data).

Our hypothesis was that isolates of $P$. infestans collected from a single focus all belong to one genotype, as the result of the successful colonization by a single genotype. For foci in potato fields, this was generally the case. Exceptions were a focus in a field with high disease intensity and a focus in which oospores were thought to be involved. In allotment gardens, where oospores are thought to be the most important infection source (M. J. Zwankhuizen, T. van der Lee, F. Govers, and J. C. Zadoks, unpublished data), a focus was found with four unique genotypes. Isolates collected from foci on refuse piles generally belonged to more than one genotype, most isolates having the predominant genotype NL-41, NL-69, NL-75, or NL-76. The occurrence of more than one genotype within a disease focus may affect the rate at which a focus expands. To our knowledge, genotypic composition of foci of $P$. infestans has not been analyzed so far.

Disease gradients. Slopes of the gradients downwind of refuse piles varied considerably. Differences might have been caused by secondary spread along the gradient or by infections arising from other sources (18). Slopes of gradients of fields downwind of refuse piles were significantly steeper than slopes of gradients downwind of organic fields $\left(-0.35\right.$ versus $\left.-0.0045 \mathrm{~m}^{-1}\right)$. Although the distance from refuse piles to target fields was roughly one-tenth of the average distance from the virtual source to the targets, the areas of the two sources differed more than a 1,000-fold. Therefore, the 100-fold difference between the two types of slope may be largely attributed to the size of the respective sources relative to that of the targets. Infested refuse piles can be regarded as point sources, whereas infested organic fields are area sources (30). Other, unknown sources could have contributed to the flattening of the gradients downwind of the organic fields. However, we estimate their effects to be limited, because the organic fields, included in the virtual source, were the only infection sources in the area where spread of disease was observed during that time. The region gradient was cone-shaped with a slope of $-0.0029 \mathrm{~m}^{-1}$, with only minor disease intensities upwind of the virtual source. The observable length of the gradient was approximately $4 \mathrm{~km}$. Fields Fc7 and Fc12 were excluded, because disease intensity in those fields was much higher than in the other fields, taking into account their distance to the virtual source. The probable reason is mismanagement, since the two growers did not check their fields regularly. Crosswind gradient analysis showed the width of the cone to be at least 0.41 radians, with the calculated bisector pointing to the east. Spread to the east is in accordance with the prevailing wind directions at this time of the year. Clear differences in disease intensities existed in the cone. If other factors are constant, these differences should only be determined by the relative position of the field in the cone (i.e., by the distance from the source along the downwind gradient) and the distance from the bisector of the cone (along the crosswind gradient). Differences in control practices (e.g., inspection frequency by the grower, and amount and type of fungicide used) and crop development confounded the theoretical pattern.

A general shortcoming in the use of disease gradients for the localization of infection sources is the disregard of the genotypic composition of target and source population (29). Unknown sources can have a profound effect on disease development in target fields (18). Therefore, we combined gradient analysis with characterization of isolates. Gradient analysis and isolate characterizations were in good agreement in this study. Consideration of the genotypes found along the region gradient revealed that the observed gradient consisted of at least two genotype-specific gradients. Genotype dependency of disease gradients might be an additional explanation of the relatively poor statistical fit $\left(R^{2}=0.44\right)$ of the gradient. Differences between the genotype-specific gradients may have occurred simply by chance, but differences in pathogenic fitness (e.g., the number of spores produced per unit of lesion area) between genotypes cannot be excluded and needs further research.

Infection sources. Both field observations and characterization of isolates suggest that infested refuse piles were major infection sources for the development of late blight epidemics in Southern Flevoland in the spring of 1994 and 1995. The decrease in number of infested refuse piles over the years was probably caused by reduced tuber infections in the autumn of 1994 and 1995, compared with 1993. The majority (74\%) of fields with early foci was associated with nearby infested refuse piles and, in most cases, putative sources and targets had the same genotypes. Ninety-one percent of the isolates from the refuse piles collected in 1994 and 1995 belonged to the predominant genotypes NL-41, NL-69, NL-75, and NL-76 (M. J. Zwankhuizen, T. van der Lee, F. Govers, and J. C. Zadoks, unpublished data). The majority (70\%) of isolates collected in the commercial fields also belonged to these genotypes.

In 1994, five infested refuse piles were found in the Nz-section of Southern Flevoland (Fig. 2), which equals 0.2 infection sources per $\mathrm{km}^{2}$ ( 25 ha of potatoes). This relatively low density of initial infection sources resulted in a general occurrence of late blight in June. Van der Zaag (27), J. C. Zadoks and H. Lohuis (unpublished data), and J. C. Zadoks and L. C. Davidse (unpublished data) identified $1,1.5$, and 0.7 foci per $\mathrm{km}^{2}$, respectively. Although other sources cannot be excluded in our study (e.g., infected seed tubers or undetected infested refuse piles), the occurrence of a general epidemic can be explained by the presence of the few initial foci found in infested refuse piles. Most infested refuse piles were found before the time growers began to apply fungicides (i.e., the first week of June). The putative increase in pathogenic fitness of the new $P$. infestans population $(8,22)$ may have contributed to a rapid spread of disease.

Van der Zaag (27) found one focus per $\mathrm{km}^{2}$ originating from an infected seed tuber in potato fields. He also identified 0.2 infested refuse piles per $\mathrm{km}^{2}$. For only one potato field was the distribution of the disease in the field found to be associated with an infested refuse pile. He concluded that refuse piles were of minor importance. Boyd (4), J. C. Zadoks and H. Lohuis (unpublished data), and J. C. Zadoks and L.C. Davidse (unpublished data) found infested refuse piles to be the major infection sources, with little or no indications that infected seed tubers had contributed significantly to disease development. However, other studies indicate that the contribution of infected seed tubers cannot be excluded. The results of Hirst and Stedman (19) suggest that foci can develop from diseased tubers by infection of above-ground plant parts via spores originating from diseased tubers and passing through the soil without invading stems. In addition, several population studies showed that seed tubers can be important as an infection source $(7,14,17)$. Moreover, our own studies (M. J. Zwankhuizen, T. van der Lee, F. Govers, and J. C. Zadoks, unpublished data) indicate that infected seed tubers might play a role in the development of disease in organic crops.

To determine whether early foci could have originated from oospores, infectivity of the soil was tested using a bioassay. None of the soil samples appeared to contain oospores. Nevertheless, characterization of isolates from disease foci suggested infection from oospores in some cases. The sensitivity of the bioassay might be too low to allow detection of infectious oospores in soil, especially when these propagules are not distributed evenly in the soil.

Volunteer plants seemed to be of minor importance, probably due to relatively low volunteer plant densities in 1994 and minor epidemics in 1995 and 1996. No foci originating from infected tubers were found, and no volunteer plants were involved in secondary spread. Although Hirst and Stedman (19) showed that the fungus can overwinter in tubers in the soil, conditions in the open field are less favorable for survival of the pathogen and development of foci than in refuse piles.

Disease gradient analysis and characterization of isolates demonstrated convincingly that at least two organic fields were major 
secondary inoculum sources in the Nz-section of Southern Flevoland in August and September 1994. Gradient analyses suggest that not all infested organic fields contributed to disease spread (e.g., field Fo3 was exempted) (Fig. 3). In 1995 and 1996, due to unfavorable weather conditions, hardly any field-to-field disease spread was observed. In 1994 and 1995, the majority of infections in organic fields probably originated from refuse piles, surrounding conventional fields, and organic seed tubers.

Some infections in the commercial potato fields could have originated from allotment gardens, but the evidence is scanty (M. J. Zwankhuizen, T. van der Lee, F. Govers, and J. C. Zadoks, unpublished data).

This study is the first to provide combined epidemiological and genotypic evidence that infested refuse piles were important sources for the establishment of early foci within fields, which may lead to a general epidemic of late blight in an agricultural area. In 1994, infested organic crops acted as late or secondary infection sources, resulting in dispersal of at least two genotypes of the late blight fungus over an area of $25 \mathrm{~km}^{2}$ in a period of 2 weeks. Effective elimination or covering of all the refuse piles is needed to prevent early introduction of late blight. The longer the epidemic is retarded, the shorter will be the period during which sexual reproduction with successful formation of oospores can occur. The foliage of organic crops has to be destroyed by flaming immediately after the first appearance of the disease in order to prevent dispersal to neighboring fields, to reduce the risk of oospore formation, and to avert infection of seed potatoes.

\section{ACKNOWLEDGMENTS}

This work was supported by the Ministry of Agriculture, Nature Management and Fisheries, and the Dutch Board of Agriculture (Landbouwschap). We thank B. Uenk and H. van Raaij for technical assistance; officers of the Plant Protection Service at Emmeloord and many other individuals, including many potato growers, for their keen observations and other assistance; and M. J. Jeger and C. D. van Loon for critically reading the manuscript.

\section{LITERATURE CITED}

1. Anonymous. 1953. Some further definitions of terms used in plant pathology. Trans. Br. Mycol. Soc. 36:267.

2. Anonymous. 1992. Biologische landbouw. Notitie 22817, nr.1, Ministerie van Landbouw, Natuurbeheer, and Visserij. SDU 's Gravenhage, the Netherlands.

3. Bonde, R., and Schultz, E. S. 1943. Potato refuse piles as a factor in the dissemination of late blight. Maine Agric. Exp. Stn. Bull. 416:229-246.

4. Boyd, A. E. W. 1974. Sources of potato blight (Phytophthora infestans) in the east of Scotland. Plant Pathol. 23:30-36.

5. Caten, C. E., and Jinks, J. L. 1968. Spontaneous variability of single isolates of Phytophthora infestans. I. Cultural variation. Can. J. Bot. 46: 329-348.

6. Croxall, H. E., and Smith, L. P. 1976. The epidemiology of potato blight in the East Midlands. Ann. Appl. Biol. 82:451-466.

7. Davidse, L. C., Henken, J., van Dalen, A., Jespers, A. B. K., and Mantel, B. C. 1989. Nine years of practical experience with phenylamide resistance in Phytophthora infestans in the Netherlands. Neth. J. Plant Pathol. 95(Suppl. 1):197-213.
8. Day, J. P., and Shattock, R. C. 1997. Aggressiveness and other factors relating to displacement of populations of Phytophthora infestans in England and Wales. Eur. J. Plant Pathol. 103:379-391.

9. Drenth, A., Goodwin, S. B., Fry, W. E., and Davidse, L. C. 1993. Genotypic diversity from Phytophthora infestans in the Netherlands revealed by DNA polymorphisms. Phytopathology 83:1087-1092.

10. Drenth, A., Janssen, E. M., and Govers, F. 1995. Formation and survival of oospores of Phytophthora infestans under natural conditions. Plant Pathol. 44:86-94.

11. Drenth, A., Tas, I. C. Q., and Govers, F. 1994. DNA fingerprinting uncovers a new sexually reproducing population of Phytophthora infestans in the Netherlands. Eur. J. Plant Pathol. 100:97-107.

12. Easton, G. D. 1982. Late blight of potatoes and prediction of epidemics in arid central Washington State. Plant Dis. 66:452-455.

13. Frinking, H. D., Davidse, L. C., and Limburg, H. 1987. Oospore formation by Phytophthora infestans in host tissue after inoculation with isolates of opposite mating type found in the Netherlands. Neth. J. Plant Pathol. 93:147-149.

14. Fry, W. E., Goodwin, S. B., Dyer, T. T., Matuszak, J. M., Drenth, A., Tooley, P. W., Sujkowski, L. S., Koh, Y. J., Cohen, B. A., Spielman, L. J., Deahl, K. L., Inglis, D. A., and Sadlan, K. P. 1993. Historical and recent migrations of Phytophthora infestans: Chronology, pathways, and implications. Plant Dis. 77:653-661.

15. Goodwin, S. B. 1997. The population genetics of Phytophthora. Phytopathology 87:462-473.

16. Goodwin, S. B., Drenth, A., and Fry, W. E. 1992. Cloning and genetic analyses of two highly polymorphic, moderately repetitive nuclear DNA's from Phytophthora infestans. Curr. Genet. 22:107-115.

17. Goodwin, S. B., Sujkowski, L. S., Dyer, A. T., Fry, B. A., and Fry, W. E. 1995. Direct detection of gene flow and probable sexual reproduction of Phytophthora infestans in northern North America. Phytopathology 85:473-479.

18. Gregory, P. H. 1968. Interpreting plant disease dispersal gradients. Annu. Rev. Phytopathol. 6:189-212.

19. Hirst, J. M., and Stedman, O. J. 1960. The epidemiology of Phytophthora infestans. II. The source of inoculum. Ann. Appl. Biol. 48:489-517.

20. Hohl, H. R., and Iselin, K. 1984. Strains of Phytophthora infestans from Switzerland with A2 mating type behaviour. Trans. Br. Mycol. Soc. 83: 529-530.

21. Hooker, W. J., ed. 1981. Compendium of Potato Diseases. The American Phytopathological Society, St. Paul, MN.

22. Kato, M., Mizubuti, E. S., Goodwin, S. B., and Fry, W. E. 1997. Sensitivity to protectant fungicides and pathogenic fitness of clonal lineages of Phytophthora infestans in the United States. Phytopathology 87:973-978.

23. Kiyosawa, S., and Shiyomi, M. 1972. A theoretical evaluation of the effect of mixing resistant variety with susceptible variety for controlling plant disease. Ann. Phytopathol. Soc. Jpn. 38:41-51.

24. Sokal, R. R., and Rohlf, F. J. 1981. Biometry, 2nd ed. W. H. Freeman Co., New York.

25. Sujkowski, L. S., Goodwin, S. B., Dyer, A. T., and Fry, W. E. 1994. Increased genotypic diversity via migration and possible occurrence of sexual reproduction of Phytophthora infestans in Poland. Phytopathology 84:201-207.

26. Van der Plank, J. E. 1963. Plant diseases: Epidemics and control. Academic Press, New York.

27. Van der Zaag, D. E. 1956. Overwintering en epidemiologie van Phytophthora infestans, tevens enige nieuwe bestrijdingsmogelijkheden. Tijdschr. Planteziekten 62:69-156.

28. Waggoner, P. E. 1952. Distribution of potato late blight around inoculum sources. Phytopathology 42:323-328.

29. Zadoks, J. C. 1988. Demonstration of long-distance dispersal in plant disease epidemiology: Methodological criteria. Int. Aerobiol. Newsl. 27:19-20.

30. Zadoks, J. C., and Schein, R. D. 1979. Epidemiology and plant disease management. Oxford University Press, Oxford. 